\title{
Management and Distribution Strategies for Dynamic Power in a Ship's Micro-Grid System Based on Photovoltaic Cell, Diesel Generator, and Lithium Battery
}

\author{
Wanneng $\mathrm{Yu}^{1,2, *}$, Suwen $\mathrm{Li}^{1}$, Yonghuai Zhu ${ }^{1}$ and Cheng-Fu Yang ${ }^{3, *}$ \\ 1 School of Marine Engineering, Jimei University, Xiamen 361021, China; suwenli@jmu.edu.cn (S.L.); \\ 201711824012@jmu.edu.cn (Y.Z.) \\ 2 Provincial Key Laboratory of Naval Architecture \& Ocean Engineering, Xiamen 361021, China \\ 3 Department of Chemical and Materials Engineering, National University of Kaohsiung, \\ Kaohsiung 811, Taiwan \\ * Correspondence: wnyu2007@jmu.edu.cn (W.Y.); cfyang@nuk.edu.tw (C.-F.Y.)
}

Received: 14 October 2019; Accepted: 24 November 2019; Published: 27 November 2019

\begin{abstract}
Combining new energy technology with electric propulsion technology is an effective way to decrease the pollution of water resources caused by cruise ships. This study examines the stable parallel operation of a ship's micro-grid system through a dynamic power management strategy involving a step change in load. With cruise ships in mind, we construct a micro-grid system consisting of photovoltaics (PV), a diesel generator (DG), and a lithium battery and establish a corresponding simulation model. We then analyze the system's operating characteristics under different working conditions and present the mechanisms that influence the power quality of the ship's micro-grid system. Based on an analysis of the power distribution requirements under different working conditions, we design a power allocation strategy for the micro-grid system. We then propose an optimization allocation strategy for dynamic power based on fuzzy control and a load current feed-forward method, and finally, we simulate the whole system. Through this study we prove that the proposed power management strategy not only verifies the feasibility and correctness of the ship's micro-grid structure and control strategy, but also greatly improves the reliability and stability of the ship's operation.
\end{abstract}

Keywords: photovoltaics; lithium battery; ship micro-grid system; fuzzy logic; power management

\section{Introduction}

To comply with the requirements of the energy efficiency design index (EEDI), the shipping industry must find ways to reduce its emissions of greenhouse gases. Low-carbon-emission shipping strategies and technologies that recently have been applied on ships in many developed countries include ship form optimization, electrical propulsion, nuclear propulsion, fuel cells, biomass fuels, and renewable energy sources [1,2].

Solar energy is an important natural resource, utilized mainly through photo-thermal and photovoltaic (PV) techniques, which are widely applied in aerospace, architecture, electrical power generation, and elsewhere [3-12]. Solar PV technology has been introduced into ships' power systems to reduce their greenhouse gas emissions, improve energy efficiency, and reinforce power system stability [13]. PV technology is mainly used in four ways on ships: as a propulsion power supply for small ships, a power supply for a ship's auxiliary machinery, a supply for general power consumption on large and medium passenger ships, and a heating source for large oil tankers [3]. Figure 1 shows 
the solar cruise ship "Shangdeguosheng", which was built for the Shanghai World Expo in 2010. Passengers can enjoy a life of leisure on the ship, such as dining and entertainment, and the ship can be used to hold important business meetings and for other functions. In 2011, the German ship "Planet Solar" was constructed (Figure 2), with its owner claiming it to be the world's largest solar-powered ship. In 2013, the sightseeing ship "Yun Dang No. 1" was navigated in Xiamen Yun Dang Lake, powered by solar energy (Figure 3). The "Cosco Tengfei" was remodeled to become China's first large automobile ro-ro ship with solar PV, shown in Figure 4.

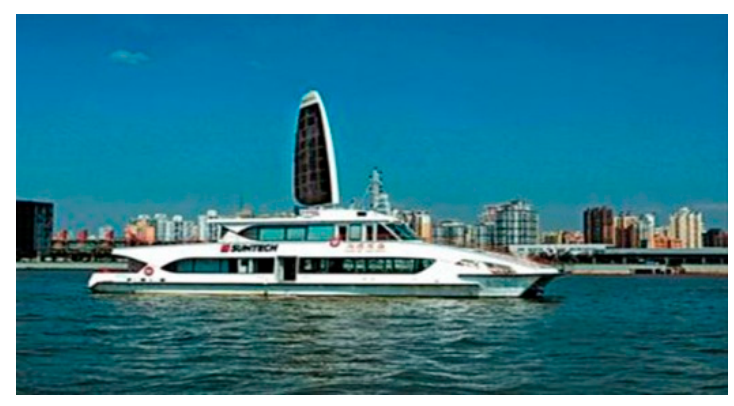

Figure 1. "ShangDeGuoSheng" solar cruise ship.

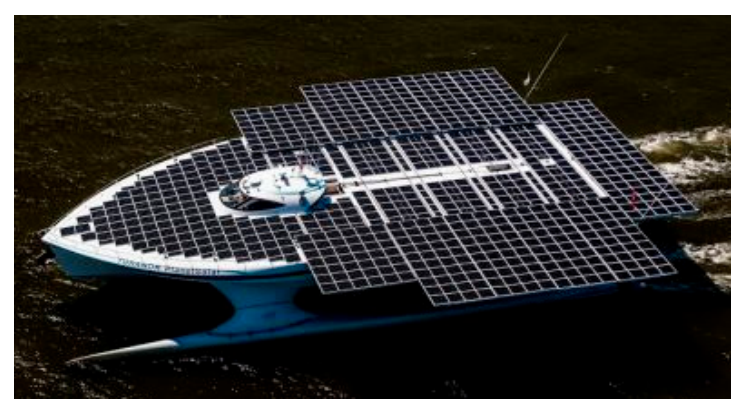

Figure 2. "Planet Solar" solar ship.

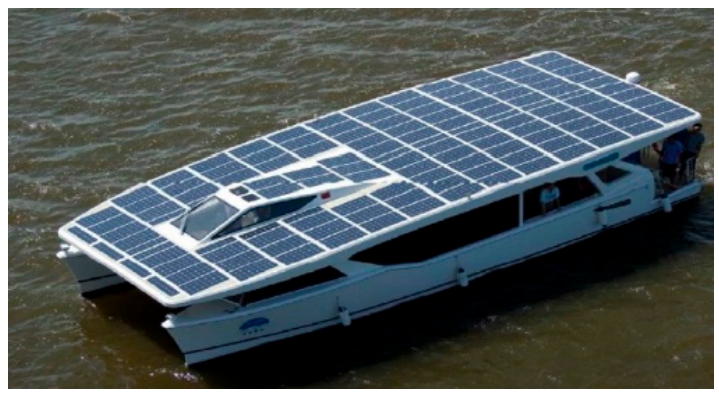

Figure 3. "Yun Dang No.1" solar cruise ship.

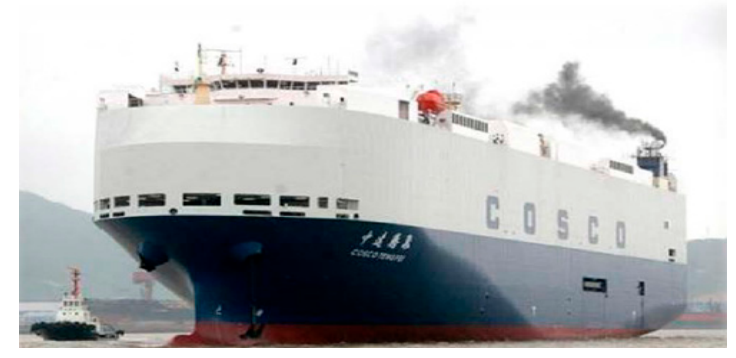

Figure 4. "Cosco Tengfei" ro-ro ship. 
Although PV technology is widely utilized in power systems on land, to the best of our knowledge, hybrid PV/diesel/battery power systems on ships have not been extensively investigated and developed, especially the use of marine micro-grid technology to manage and control hybrid power systems on ships. Glykaset et al. discussed PV systems applied to merchant marine vessels to reduce fuel costs [14]. A stability assessment and economic analysis of a hybrid PV/DG ship system are presented by Tsekouras et al. [15]. Adamo et al. offered a preliminary analysis of reducing the emissions from an electrical ship in a berth [16]. Thus, Wen et al. performed a cost analysis using a particle swarm optimization algorithm to find the optimal size and capacity for various types of energy storage systems [17]. And, Lan et al. proposed a method for determining the ideal size for a PV power generation system; a diesel generator and an energy storage system were designed in a ship's stand-alone power system with the aim of minimizing investment cost, fuel cost, and $\mathrm{CO}_{2}$ emissions [13].

Tang [18] proposed a novel structure for a large-scale PV array and its controls, designed for the illumination unit of a ship's power grid. Lee et al. [19] reported on the experimental results from the operation of a prototype green ship on Geoje Island, South Korea. In [20], Sun and colleagues built a simulation model of a PV-driven power system for a ship, based on a PSCAD/EMTDC platform. The use of new energy technologies in ships has so far been limited to the development of "green" touring vessels.

Yu et al. had developed multi-energy ship micro-grid energy control system based on solar lithium battery and diesel generator set for cruise ships and proposed the energy distribution control strategy according to the requirements of safe and stable operation, and they had verified the feasibilities on the actual ships [21,22]. Banaei et al. conducted a study on all-electrical propulsion ships, which consisted of fuel cells, batteries, PV, and two diesel generators [23]. The battery state of charge (SOC) was divided into three different states, in which SOC $>\mathrm{SOC}_{\text {high, }} \mathrm{SOC}_{\text {low }}<\mathrm{SOC}<\mathrm{SOC}_{\text {high, }}$ and $\mathrm{SOC}<\mathrm{SOC}_{\text {low }}$. They also proposed the different energy management strategies in different states, for that the diesel generators, energy storage systems, and fuel cells were rationally utilized. For the ship's micro-grid composing of diesel generator and other energy systems, Kuo et al. had proposed a storage for the ship's power supply mode. The proposed storage could be determined according to the SOC state of energy storage system and it achieved the effects of reducing the fuel consumptions and exhausted emissions of the diesel engine [24].

However, all of above statements were investigated for the managements of energy sources in static situations, and no dynamic situations were studied. Until now, only few studies were focused on the dynamic control of ship's micro-grid, but there were many related researches on terrestrial micro-grid. Kong et al. proposed a three-stage proportional plus derivative control (PD) preemptive dynamic scheduling strategy, which could overcome the problem of dynamic control and the PD control was easy to cause oscillation, but the settings of three time constants increased the difficulty of system design [25]. Because the different micro-grid systems have different time constants, so it is not an almighty method. Ding et al. proposed a method based on fuzzy control strategy for battery energy storage system to improve the transient stability of power grid at when the input of fuzzy controller had the problem of frequency difference [26]. Above two methods were investigated to suppress the frequency difference, but both would cause a delay in control. Li analyzed the mathematical model of diesel generator, and he obtained the reason of frequency fluctuation during load abrupt change [27]. Also, Li had proposed the active compensation strategy of current feed forward compensation and PD control algorithm, but this method was easy to cause the high frequency oscillation.

These applications often have shortcomings, such as frequency fluctuation, high cost, and complicated control systems. We therefore propose management and distribution strategies for dynamic power by combining PV, diesel generator, and lithium battery. Via the fuzzy control and compensation method of the ship's micro-grid system, we were able to obtain optimal compensation power. After taking into consideration the balance between sailing mileage and economic efficiency, as well as how to integrate PV, DG, and lithium battery characteristics, we investigated a ship's micro-grid 
system to combine those three power sources. Therefore, this investigated article was based on the dynamic research of terrestrial micro-grid, which combined with the characteristics of the static power allocation strategy and dynamic power allocation strategy of ship's micro-grid. The strategies for the frequency fluctuation during the sudden change of load in the PV-diesel generator-battery operation mode were analyzed and investigated. The characteristics of the energy storage system could be utilized to respond quickly, and the output or developed power could be used to lower down the frequency fluctuation, and a dynamic energy scheduling strategy was put forward based on current the feed-forward and fuzzy control.

\section{Modelling of the Ship's Micro-Grids System}

Unlike in previous studies, we considered step changes in strong coupling, the great complexity of the random changes that occur in a ship's power system, and step changes in loads. We then present a novel dynamic power distribution strategy for a ship's micro-grid system. The topological structure is shown in Figure 5 and can be described as follows [28,29]:

(1) The ship's micro-grid system is composed of a diesel generator, a lithium battery, and PV solar cells, and the PV and lithium-ion-based battery are connected by inverters to the AC grid bus, which can supply power in parallel with the diesel generator.

(2) To use the renewable energy more effectively, the micro-grid power system is mainly operated by the inverter, while the diesel generators are used as an auxiliary or emergency power source.

(3) The micro-grid system has many operation modes, depending on the ship's navigation state. For example, when the ship is in berth with sufficient sunlight, solar power will charge the lithium battery and supply power for the daily living equipment, and the diesel generator will be idle. When the ship is under normal sailing conditions and the voyage is short, propeller power and daily living power will be jointly supplied by the solar and lithium batteries, and the diesel generator will remain idle. When the ship is under normal sailing conditions and the voyage is long, propeller power and living power will be jointly supplied by the solar and lithium batteries, and the diesel generator and energy management control strategy for the ship's micro-grid system will work together, which is the primary working mode investigated in this paper.

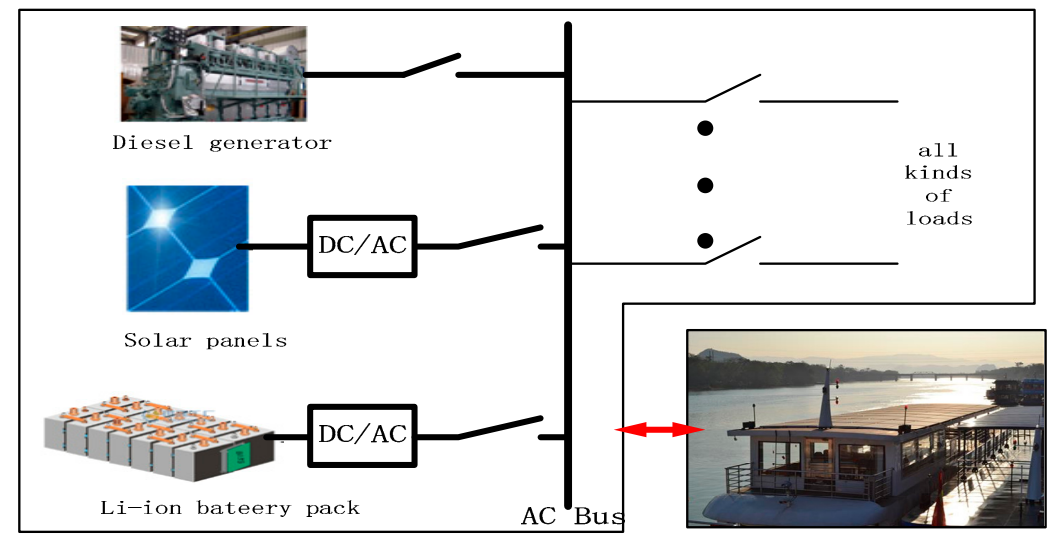

Figure 5. Proposed structure of ship's micro-grid system.

The ship's micro-grid system is very different from a traditional land micro-grid system, as the ship's has no unified dispatch center and the operating conditions are more complicated. In the topology described above, one of the frequent operation modes is very complex because the multiple power sources are arranged in parallel. To better analyze the micro-grid system's performance in this mode, using mathematical analysis of the power supply mechanisms for the various energy sources, we established a simulation model of the micro-grid system. This provides the foundation for further research on the strategy for controlling the micro-grid system under changing dynamic loads. 


\subsection{The Dynamic Characteristics of the Diesel Generator}

The electromagnetic torque formula of for the synchronous generator can be expressed as Equation (1) as when the salient effect is ignored:

$$
T_{e}=E_{p}{ }^{\prime} i_{p}
$$

In this formula, $E_{\mathrm{p}}{ }^{\prime}$ is the instantaneous electromotive force (EMF) of the generator and $i_{p}$ is the stator current of the $p$ axis. The diesel motor drives the synchronous generator's rotation, and the stator winding of the synchronous generator takes the induction EMF by cutting the magnetic line motion in the magnetic field, providing electrical energy in the case of an external load. When the load alters suddenly, so does its active current. According to Equation (1), the electromagnetic torque also changes.

According to [30], the functioning of an output diesel-engine speed-control system can be expressed as:

$$
\omega(s)=\frac{K\left(1+T_{2} s\right)\left(1+T_{3} s\right)}{M} \omega_{r e f}(s)-\frac{s\left(1+T_{1} s\right)\left(1+T_{4} s\right)\left(1+T_{5} s\right)\left(1+T_{d} s\right)}{M} T_{e}(s)
$$

where $M=T_{j} s^{2}\left(1+T_{1} s\right)\left(1+T_{4} s\right)\left(1+T_{5} s\right)\left(1+T_{d} s\right)+K\left(1+T_{2} s\right)\left(1+T_{3} s\right)$, and $T_{1}, T_{4}, T_{5}$, and $T_{d}$ are the small time constants, $T_{j}$ is a time constant in the diesel engine model, $\mathrm{K}$ refers to the parameter of transfer function, subscript symbol $s$ refers to the Laplace transform of model, and Te refers to the electromagnetic torque. If we set $T=T_{1}+T_{4}+T_{5}+T_{d}$, then $M=T_{j} s^{2}(1+T s)+K\left(1+T_{2} s\right)\left(1+T_{3} s\right)$. Thus, the output of the system can be expressed as:

$$
\omega(s)=\frac{K\left(1+T_{2} s\right)\left(1+T_{3} s\right)}{M} \omega_{r e f}(s)-\frac{s(1+T s)}{M} T_{e}(s)
$$

From Equation (3) we see that the output is determined by the system input volume $\omega_{\text {ref }}(s)$ and $T_{e}(s)$. The transfer function $\omega_{r e f}(s)=0$ can be obtained under load disturbance. The transfer function $\mathrm{G}(\mathrm{s})$ can be then expressed as:

$$
G(s)=\frac{\omega(s)}{T_{e}(s)}=\frac{-s(1+T s)}{M}
$$

\subsection{The Model of the PV Cells}

PV cells are semiconductor devices based on the PV effect of semiconducting materials with a PN junction and have the function of directly converting sunlight into electrical energy. According to [31], when sunlight shines on PV cells, the electrons in the $\mathrm{P}$ region move to the $\mathrm{N}$ region, resulting in a large amount of electrons accumulating on the receivers.

The PV battery equivalent circuit model is shown in Figure 6, where $I_{p h}$ is a photo-generated current whose magnitude depends on the light intensity $S$ and temperature $T$, and which acts as a controlled current source; $I_{d}$ is a voltage generated by a reactive PN junction of voltage $V ; I_{s h}$ is the short-circuit current caused by leakage from the PV cells; $R_{s}$ and $R_{s h}$ are the series resistance and parallel resistance of the PV cells; $V$ is the PV output voltage; and I is the PV output current. The output current of the PV cells can be obtained from the equivalent circuit diagram and Equation (5):

$$
I=I_{p h}-I_{o s}\left\{\exp \left[\frac{q\left(V+I R_{s}\right)}{A K T}\right]-1\right\}-\frac{V+R_{s} I}{R_{s h}}
$$

$I_{p h}$ is determined thus:

$$
I_{p h}=I_{s c}=I_{s c r}\left[\frac{S}{S_{r}}+k_{i}\left(T-T_{r}\right)\right]
$$


$I_{o s}$ is determined thus:

$$
I_{o s}=I_{o r}\left(\frac{T}{T_{r}}\right)^{3} \exp \left[\frac{q E_{g}}{n K T_{r}}-\frac{q E_{g}}{n K T}\right]
$$

In Equation (5), $I_{p h}$ is the photo current; $I_{o s}$ is the diode reverse saturation current; $q$ is the electron constant, $1.602 \times \mathrm{e}^{-19}(\mathrm{C}) ; V$ and $I$ are the PV output voltage and current; $R_{s}$ is the series resistance; $R_{s h}$ is the parallel resistance; $A$ is the diode characteristic fitting coefficient; $K$ is the Boltzmann constant, with a value of $1.831 \times \mathrm{e}^{-23}(\mathrm{~J} / \mathrm{K}) ; T$ is the PV cell working temperature in Kelvin; $I_{s c r}$ is the short-circuit current under the conditions of solar radiation intensity $S_{r}=1000 \mathrm{~W} / \mathrm{m}^{2}$ and temperature $T_{r}=25^{\circ} \mathrm{C}$; $k_{i}$ is the short-circuit current temperature coefficient; $I_{o r}$ is the dark saturation current under $T_{r} ; E_{g}$ is the forbidden band width of the semiconductor material; and $N$ is the junction constant, which is 1.5. The electrical characteristics of the PV cells are shown in Figure 7.

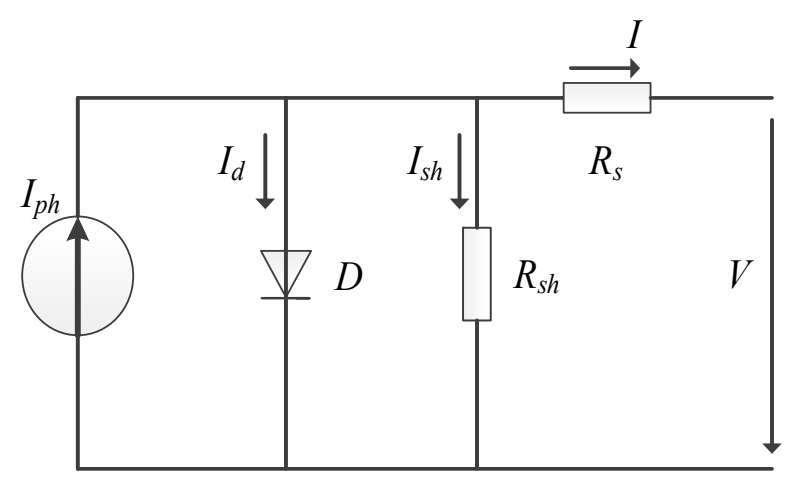

Figure 6. Equivalent circuit of photovoltaic cells.

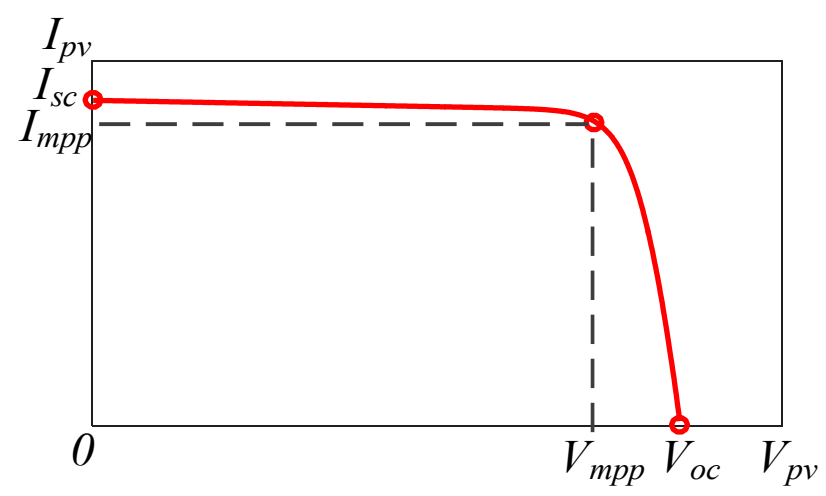

Figure 7. Characteristic of photovoltaic cells.

According to the actual needs and electric parameters, the PV cells should be connected in series or in parallel. The output current of each PV cell can then be expressed as:

$$
I=N_{p} I_{s c}-N_{p} I_{o s}\left\{\exp \left[\frac{q\left(V+I R_{s e}\right)}{N_{s} n K T}\right]-1\right\}
$$

In Equation (8), where $N_{p}$ and $N_{s}$ are the number of the PV cells' strings and parallel connections, and $R_{s e}$ is the equivalent series resistance of the PV cells after series and parallel connection.

\subsection{The Model of the Lithium Iron Phosphate Battery}

Recently, battery technologies based on lithium compounds have reduced cost and improved performance in terms of increased energy density. We used a $\mathrm{LiFePO}_{4}$ battery as the power battery for the system, a type widely used in automobiles. Ships are generally less sensitive to weight restrictions than cars are, so more energy can be stored in a ship, which has boosted interest in using purely electric cruise ships based on lithium batteries. According to [32], models for the charge or discharge 
processes of ships can use the improved Shepherd equation, expressed in Equations (9) and (10), which disregards the influence of temperature on batteries. When batteries are in the discharge and charge processes, their voltage can be expressed thus:

$$
\begin{gathered}
V_{b a t t}=E_{0}-K \frac{Q}{i t-0.1 Q} \times i^{*}-K \frac{Q}{Q-i t} \times i t+A \exp (-B \times i t) \\
V_{b a t t}=E_{0}-K \frac{Q}{Q-i t} \times i^{*}-K \frac{Q}{Q-i t} \times i t+A \exp (-B \times i t)
\end{gathered}
$$

where $V_{\text {batt }}$ is the battery terminal voltage, $E_{0}$ is the nominal voltage, $K$ is the polarization constant, $Q$ is the battery capacity, $i^{*}$ is the filter current, $A$ is the exponential voltage, and $B$ is the exponential time constant.

\subsection{Working Principle and Model of Inverter Power}

Considering that the ship's distribution mode is mainly a three-phase, three-wire system, a relatively simple three-phase full bridge topology is applied for the main power circuit. This is shown in Figure 8, where the LC filter is selected for the filter and $U_{\mathrm{dc}}$ is used as the DC voltage; $u_{\mathrm{ia}}, u_{\mathrm{ib}}$, and $u_{\mathrm{ic}}$ act as the inverter output voltages; $i_{\mathrm{ia}}, i_{\mathrm{ib}}$, and $i_{\mathrm{ic}}$ act as the inverter output currents; $u_{\mathrm{sa}}, u_{\mathrm{sb}}$, and $u_{\mathrm{sc}}$ are the bus voltages; $i_{\mathrm{sa}}, i_{\mathrm{sb}}$, and $i_{\mathrm{sc}}$ are the bus currents; $\mathrm{L}$ is the filtering inductance; and $\mathrm{C}$ is the filtering capacitance.

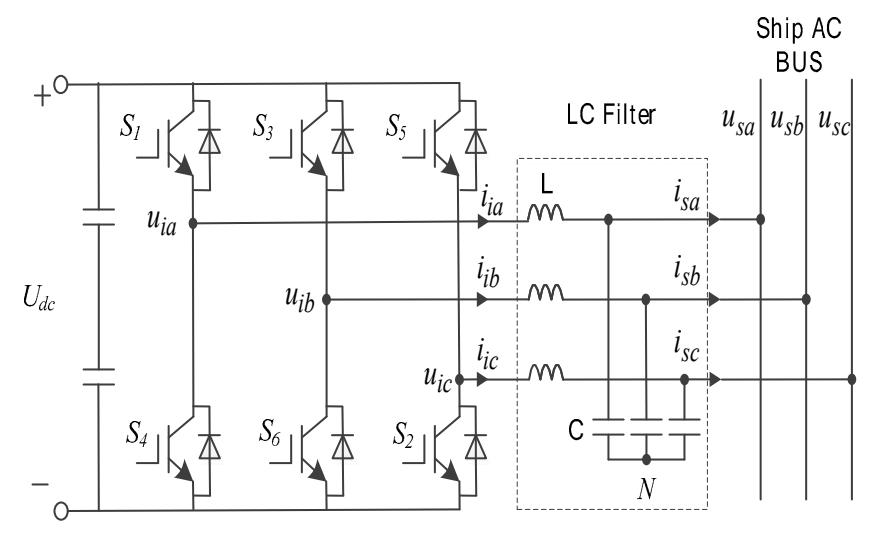

Figure 8. Circuit of the investigated inverter.

The inverter control strategy can be divided into three control modes: constant power control (PQ), constant voltage and frequency control $(\mathrm{V} / \mathrm{f})$, and dropping control. Depending on the requirements of different operation modes, different control algorithms can be selected to match each mode. The main purpose of this paper is to investigate the best operation mode for parallel inverters and then better utilize the solar energy of PV cells, so we adopted the PQ control method. The voltage/current values on the $d q$ axis can be obtained by PARK transformation, and according to instantaneous power theory, the active and reactive power outputs from the inverter can be expressed as:

$$
\left\{\begin{array}{l}
P=u_{s d} i_{s d}+u_{s q} i_{s q} \\
Q=u_{s q} i_{s d}-u_{s d} i_{s q}
\end{array}\right.
$$

Selecting the $\mathrm{d}$ axis and the voltage/current vector in the same direction, the following formula can be obtained:

$$
\left\{\begin{array} { l } 
{ P = u _ { s d } i _ { s d } } \\
{ Q = - u _ { s d } i _ { s q } }
\end{array} \Rightarrow \left\{\begin{array}{l}
i_{s d r e f}=\frac{P_{r e f}}{u_{s d}} \\
i_{\text {sqref }}=\frac{-Q_{r e f}}{u_{s d}}
\end{array}\right.\right.
$$


According to Equation (12) and under the dp axis, the active power $P$ is determined by $u_{\mathrm{sd}}$ and $i_{\text {sd }}$, while the reactive power $Q$ is determined by $u_{\mathrm{sd}}$ and $i_{\mathrm{sq}}$. The decoupling control of active power $P_{\text {ref }}$ and reactive power $Q_{\text {ref }}$ is realized by controlling $i_{\text {sdref }}$ and $i_{\text {sqref }}$, respectively, so that the voltage of the micro-grid system is unchanged. To control the current, the circuit equation of the inverter can be obtained from Figure 9:

$$
\left\{\begin{array}{l}
L \frac{d i_{s d}}{d t}=u_{l d}-u_{s d}+w L i_{s q} \\
L \frac{d i_{s q}}{d t}=u_{l q}-u_{s q}+w L i_{s d}
\end{array}\right.
$$

Using Equations (12) and (13) we can obtain the structural diagram of the PQ control, as shown in Figure 9. From this figure the inner ring current references, $i_{\text {dref }}$ and $i_{\text {qref }}$, are obtained from the power references, $P_{\text {ref }}$ and $Q_{\text {ref, }}$ to divide the voltage $u_{\mathrm{sd}}$ in the outer ring. PI control is carried out using the difference between the currents references and the actual output currents $i_{\mathrm{sd}}$ and $i_{\mathrm{sq}}$, and the modulated signals $u_{\text {dref }}$ and $u_{\text {qref }}$ are obtained through feed-forward compensation and cross-coupling compensation.

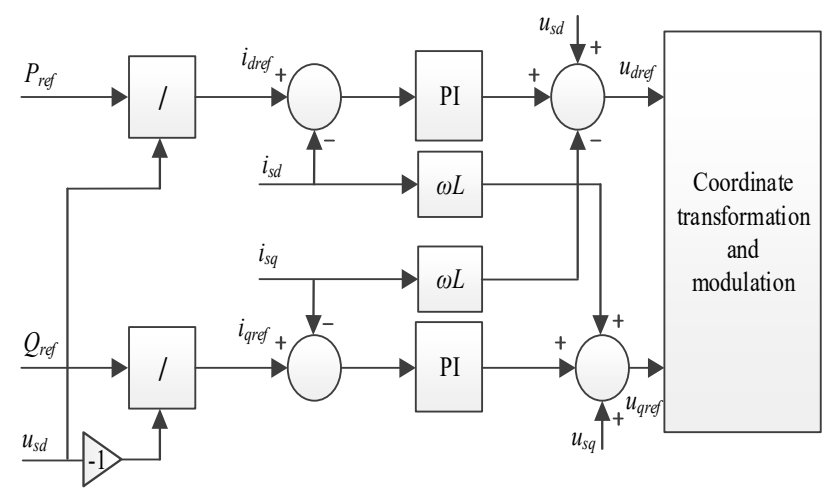

Figure 9. Power control (PQ) control strategy of inverter.

\subsection{The Simulation Model of the Ship's Micro-Grid System}

Combined with the proposed topological structure, the simulation model of the ship's micro-grid system is established using the MATLAB Simscape component libraries and modules, as presented in Figure 10.

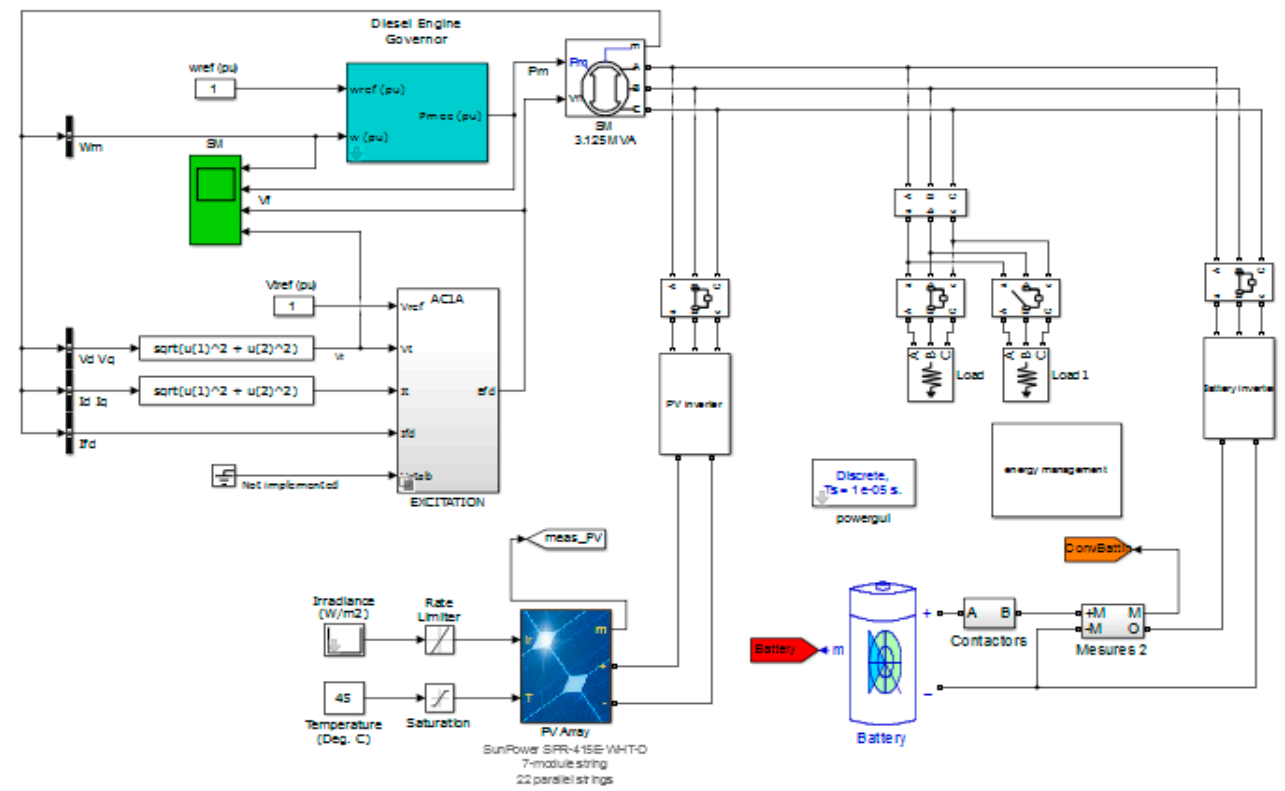

Figure 10. Simulation model of the proposed ship's micro-grid system. 


\section{Analysis of the Operation Characteristics in Parallel of the Ship's Micro-Grid System}

According to the design of ship's micro-grid system, the system's voltage and frequency were supported by the diesel generator, which provided the main power supply, and the sources from the inverter of solar PV cells and lithium batteries both were used according the following algorithm. Assuming that the solar power output was maximum and constant, the power distribution of the micro-grid system could be determined by controlling the power output of the lithium battery pack. Based on the characteristics of the marine electrical propulsion system, this article studies the micro-grid energy management strategy for the sudden change in load, which can improve the power quality (frequency) of the ship's micro-grid under dynamic load. This strategy is based on the assumption that the output of PV power generation system remains constant, and we do not explore the complex dynamics of PV power generation system. Since this study is based on the output of different power generation units equal to the load power (conservation of energy), the PV output variation can also be considered as sudden load change, so the research conclusion can also be used for PV output variation. From this point, the proposed system can still control the actual PV channels (practical PV panels).

The governor characteristic (power-frequency characteristic curve) of the diesel generator is shown in curve 1 of Figure 11 [30]; this is also called the first adjustment rule between output power and power frequency. To stabilize the frequency around the ratings value, the throttle can be adjusted according to the output power, which shifts the characteristic curve up and down; this is called the second adjustment rule. The output frequency of the lithium battery inverter follows the frequency of the main power because the current-following algorithm is adopted. The output frequency is independent of the output power, which is determined by a given PQ value. The power-frequency characteristic of the lithium battery inverter is shown in curve 2 of Figure 11 [31]. The output frequency of the solar inverter is also followed by the main power frequency, and it is independent of the output power. The output power is determined by the maximum power point tracking (MPPT) algorithm, and the power-frequency characteristic of the solar inverter is shown in curve 3 of Figure 11. The effect of load change on frequency fluctuation in the ship's micro-grid system can be analyzed as follows.

Assuming that the ship's micro-grid system is in stable operation at A point (rated frequency $f_{\mathrm{n}}$ ) under the certain working conditions in Figure 11, the solar output power is $P_{1}$, the output power of the lithium battery pack is $P_{2}$, and the output power of the diesel generator is $P_{3}$. Load increase $\Delta P=P_{4}-P_{3}$ always happens suddenly. When we use the PQ algorithm for inverter operation, $\Delta P$ will be borne by the diesel generators only because the power outputs of the solar PV and batteries are constant values. From Figure 11, we can describe the regulation process for static system frequency. At first, the power frequency will adjust according to curve 1 and the system operation point from $\mathrm{A}$ to $B$. Then, the diesel throttle will be controlled to change the system's operation point from $B$ to $C$ (curve 4). For better operation, we postulate the initial conditions in which the system load is $80 \mathrm{~kW}$, the power output of the PV array controlled by the MPPT algorithm is $15 \mathrm{~kW}$, the power output of the energy storage battery is $20 \mathrm{~kW}$, the remaining $45 \mathrm{~kW}$ of power is borne by the diesel generators, and the system reaches stable operation status $2 \mathrm{~s}$ after the simulation start. When $\mathrm{t}=4 \mathrm{~s}$, the load increases from 0 to $30 \mathrm{~kW}$ with a step increase of $5 \mathrm{~kW}$. The simulation results of the system's corresponding dynamic frequency response are shown in curve 7 to curve 1 of Figure 12.

The above analysis of system static output shows that when the load power increases, the system's frequency drops from $f_{n}$ to $f_{1}$. If the system is not controlled, the frequency fluctuation will inevitably affect the system's power quality. Especially during dynamic system processes, when the mutation load increases, the harmonic increase in inverter power output is largely due to the frequency fluctuation overshoot. That condition not only will reduce the power grid's power quality but also will make the grid collapse in a serious situation (such as the propeller touching bottom). 


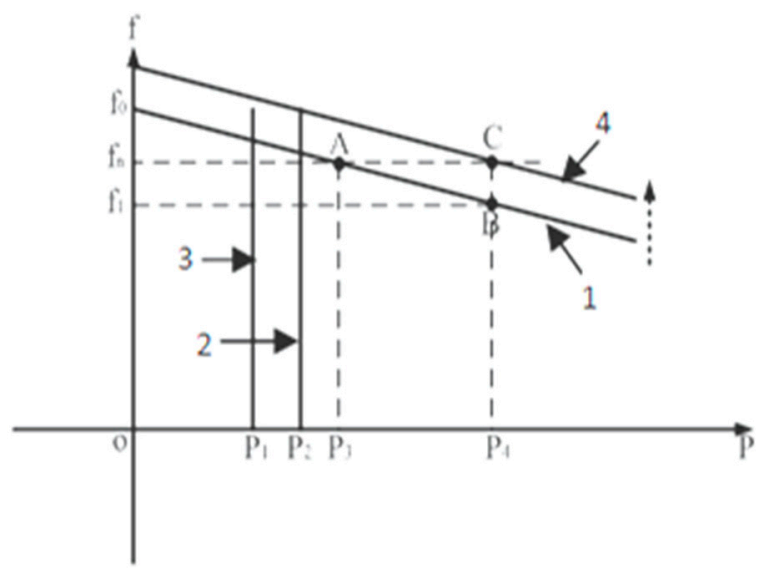

Figure 11. Frequency static regulation process.

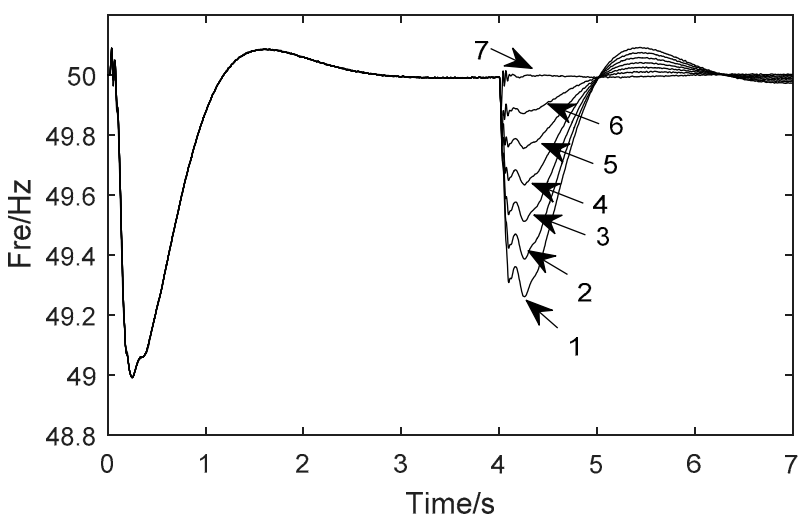

Figure 12. The system's corresponding frequency dynamic response.

\section{The Dynamic Power Distribution Strategy of the Ship's Micro-Grid System}

\subsection{Analysis of the Dynamic Power Distribution Strategy}

Because of the transient nature of the step load, the operation of impulsive power demands very high amplitude. Diesel generators are not capable of supporting transient load requirements because they need to operate constantly for a relatively long time to control the inertia of the fuel valves, combustors, and other mechanical components [33]. For supplying transient power, the lithium battery system is capable of supporting sudden changes in load and can help maintain the frequency stability of the micro-grid bus with its high power density. The main control progress of the micro-grid system is shown in Figure 13 and can be described as follows.

First, we assume that the system operates stably at point $A$ and the load increases suddenly by $\Delta P=P_{4}-P_{3}$ at a certain moment. If the reference value for the output power of the lithium battery inverter regulated using the $\mathrm{PQ}$ algorithm is changed from $P_{2}$ (curve 2) to $P_{21}$ (curve 5) at that time, and the increase in output power of the lithium battery is controlled by $P_{21}-P_{2}=P_{4}-P_{3}=\Delta P$, the working state of the micro-grid system will remain unchanged for the power output of the solar and diesel generators, and the load of the mutation will be borne entirely by the lithium battery pack. The frequency of the micro-grid system will thereby be kept stable throughout the load mutation. However, the output power $P_{2}$ from the package of lithium batteries is the optimized conditions of the micro-grid system. If the micro-grid system continues in this situation, a large current will be discharged from the lithium battery, negatively affecting its performance and lifetime. Therefore, the load of the lithium battery pack must be transferred to the diesel generator sets gradually.

According to the working characteristics of lithium battery, the optimal range of output capacity is $30-70 \%$, and the maximum short-term discharge current cannot exceed 3C. In this study, the capacity of lithium battery pack is $53 \mathrm{kWh}$ and the maximum output is set as $53 \mathrm{~kW}$ in simulation. If the load of 
system is suddenly increased to $80 \mathrm{~kW}$, then $27 \mathrm{~kW}$ can be directly generated by the diesel generator. Curve 5 represents the characteristic curve of output power-frequency, which is generated by the reverse power supply of the lithium battery pack. The output power-frequency characteristic of the lithium battery changes from curve 5 to curve 2, and the frequency characteristic of the output power of the diesel generator set changes to curve 4 from curve 1 . The output power of the lithium battery pack decreases from $P_{21}$ back to $P_{2}$, and the output power assumed by the diesel generator increases from $P_{3}$ to $P_{4}$. Through this method of control, the total sudden increase in load is borne by the diesel generators, while the output power of the lithium battery pack returns to the original working-state value, and the micro-grid system reaches stable functioning at point $C$.

We were able to conclude that the frequency of the micro-grid system can be kept stable throughout load changes if an effective control strategy is developed. According to the above analysis, the key to the system's dynamic control process is the precise measurement of the output power reference value $P_{21}=P_{2}+\Delta P$ and the algorithm for power transfer control in the lithium battery inverter source. The first part of the output power reference to value $P_{2}$ is the output power of the lithium battery inverter when the micro-grid system is operated at point $\mathrm{A}$, before the power changes. The reference value is given by optimizing the precision predictions for the PV output power, battery pack capacity, load demand, and real-time output power of the diesel generators. The second part of the output power reference value $\Delta P$ needed to be tested and calculated. To do this, we proposed a dynamic control strategy based on current compensation and fuzzy control, which assumed that load power was dependent on and proportional to the current and that the response speed of the current was faster than the response speed of the diesel engine. Compared the results in Figures 11 and 13, Figure 11 shows that if the proposed algorithm is not used as a control strategy, the frequency will have large fluctuation. Nevertheless, Figure 13 shows that as the proposed control strategy is used to control the energy system, the frequency fluctuation will be greatly reduced and the power quality of the grid will be greatly enhanced. The frequency of the micro-grid system will thereby be kept stable even the load has apparent frequency fluctuation.

This strategy can improve the dynamic and static response performances for frequency feedback and give the lithium battery inverter system better dynamic response performance and precision. The characteristics of the rapid output power of the lithium battery energy storage system suggest that the frequency fluctuation of the system under load mutation is significantly reduced, and the power quality of the ship's micro-grid system is improved. The results are also applicable if there is a sudden decrease in the output of the solar power generation system, meaning the strategy can effectively reduce the influence of intermittent solar characteristics on the system and greatly improve the stability of system operation.

The control strategy for the compensation current is dependent on the actual change in current value to control the output power reference $\Delta P_{1}$ of the whole system. The deviation problem is solved by frequency feedback, which can be achieved using a fuzzy control algorithm. This keeps the input at $\Delta f$ and $\mathrm{d} \Delta f / \mathrm{d} t$, the output power is reference $\Delta P_{2}$ of the whole system, and better dynamic performance is achieved. The input parameters of the fuzzy control algorithm are the difference $\Delta f$ between real frequency $f$ and a given reference frequency $f_{\text {ref }}$ and the change rate in the difference $\mathrm{d} \Delta f / \mathrm{d} t$. The output power of the system will be referred to $\Delta P_{2}$ to realize feedback control over the frequency. This will further improve the dynamic and static performance of the system. In this situation, the reference output power of the system is $\Delta P_{2}$; feedback control over the frequency is implemented, and the system's dynamic and static performance are further improved. Given the limited output capacity of the battery pack, we adopt the amplitude limitation control links in the system control strategy. A schematic diagram of the dynamic control strategy for the ship's micro-grid system is shown in Figure 14. 


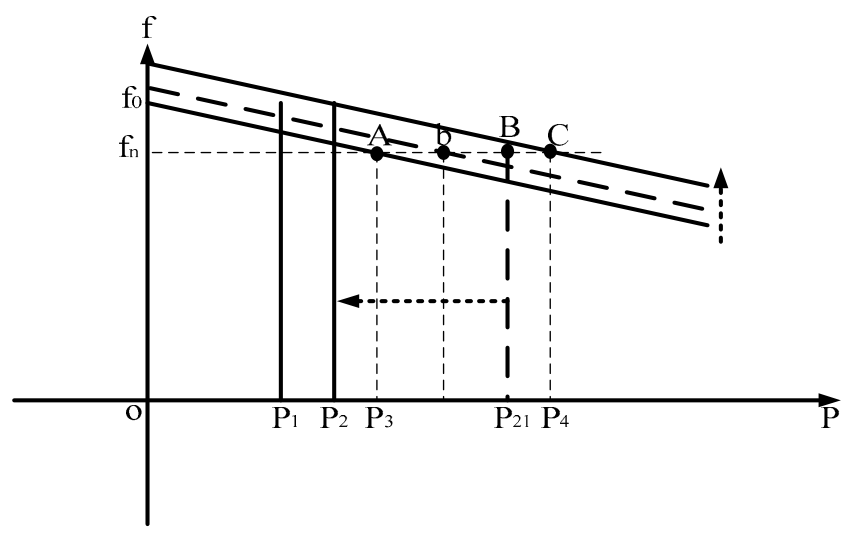

Figure 13. The proposed static frequency regulation process.

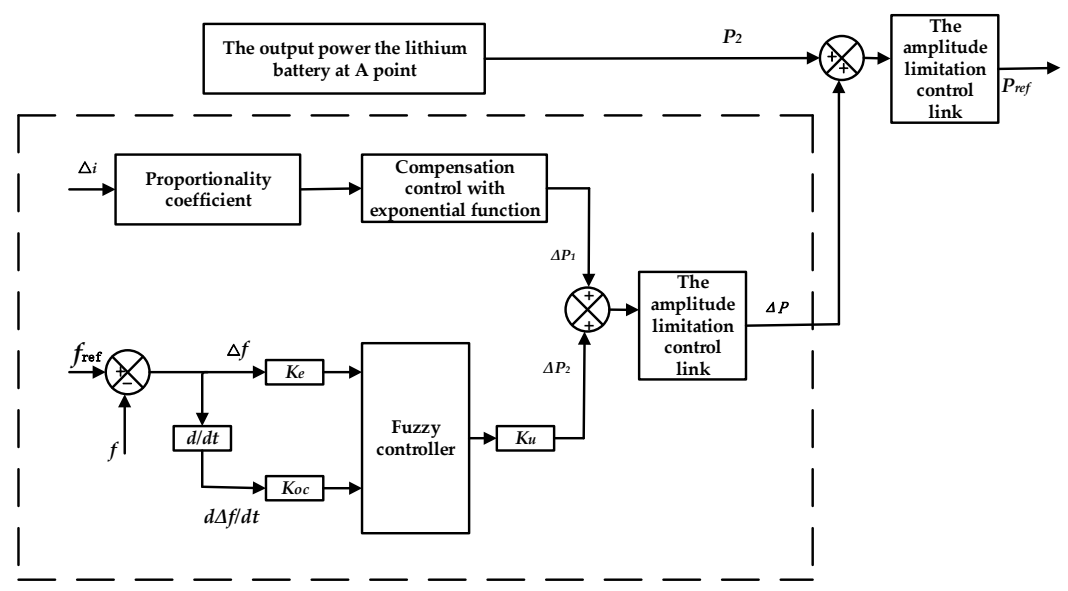

Figure 14. Proposed dynamic control strategy.

\subsection{Controller Design}

To meet the requirements for dynamic control and smooth load transfer, the current compensation power reference value is changed according to an exponential function. The time domain expression of this exponential function is shown in Equation (14):

$$
\Delta p_{1}(t)=A \times e^{-\frac{t}{\tau}}
$$

where $A$ is the initial value and $\tau$ is the time constant ( $\tau=4$ for simulation purposes). The waveform of the function is shown in Figure 15. The function value $\Delta P_{1}(t)$ is reduced from the beginning $A$ to zero, and the time constant $\tau$ determines the attenuation speed of the value $\Delta P_{1}(t)$. The fuzzy controller is equivalent to a PD controller, having the characteristics of a PD controller and significant robustness [34]. First, the fuzzy controller is used to blur the input value, then fuzzy reasoning is carried out according to the designed fuzzy control rules, and the fuzzy quantity is ambiguity resolved to obtain a clear value. In this study, the capacity of lithium battery pack is $53 \mathrm{kWh}$, which is set as the maximum output in simulation. When the increased load is greater than the difference value between $70 \%$ rated capacity of the lithium battery and the current capacity of the assembled lithium battery, the output of the assembled lithium battery will be controlled as the difference value, and the other part of the capacity will be loaded by the diesel generator set. Therefore, the value of $A$ varies according to the situation, which is related to the battery discharge current and load variation. In general, the value of $A$ is linearly related to the discharge current value of lithium battery.

The basic domain of input $\Delta f$ and $\mathrm{d} \Delta f / \mathrm{d} t$ is [ $-2.5+2.5],[-15+15]$, and the quantifying factors $K_{e}$ and $K_{e c}$ are 30 and 2, respectively. According to the control's requirements, the input value is divided into seven fuzzy sets: negative big $\{N B\}$, negative middle $\{N M\}$, negative small $\{N S\}$, zero 
$\{Z \mathrm{O}\}$, positive small $\{\mathrm{PS}\}$, positive middle $\{\mathrm{PM}\}$, and positive big $\{\mathrm{PB}\}$. When the errors of $\{\mathrm{NB}\}$ and $\{\mathrm{PB}\}$ are large, the Gaussian subordinating degree function is used to improve stability. The rest value is used with the triangle membership function to improve resolution and control sensitivity. The basic domain of output is [-3000,3000], and the proportion factor is 3 , which is divided into seven fuzzy subsets: negative big $\{N B\}$, negative middle $\{N M\}$, negative small $\{N S\}$, zero $\{Z O\}$, positive small $\{\mathrm{PS}\}$, positive middle $\{\mathrm{PM}\}$, and positive big $\{\mathrm{PB}\}$, and the triangle membership function is applied. The input and output functions of the membership function are shown in Figures 16-18. Based on the control requirement, when the frequency change and frequency change rate are larger, the power reference value $\Delta P_{2}(t)$ should be increased to improve dynamic performance and reduce error. In other circumstances, the reference value $\Delta P_{2}(t)$ should be reduced to avoid overtones, and then the fuzzy control rule in Table 1 is available. The control quantity of power output $\Delta P_{2}(t)$ must be determined. According to a fuzzy subset of the output in Table 1, the gravity method is used to solve the ambiguity $[35,36]$, and $\Delta P_{2}(t)$ is controlled by timing the proportional factor $K_{u}$.

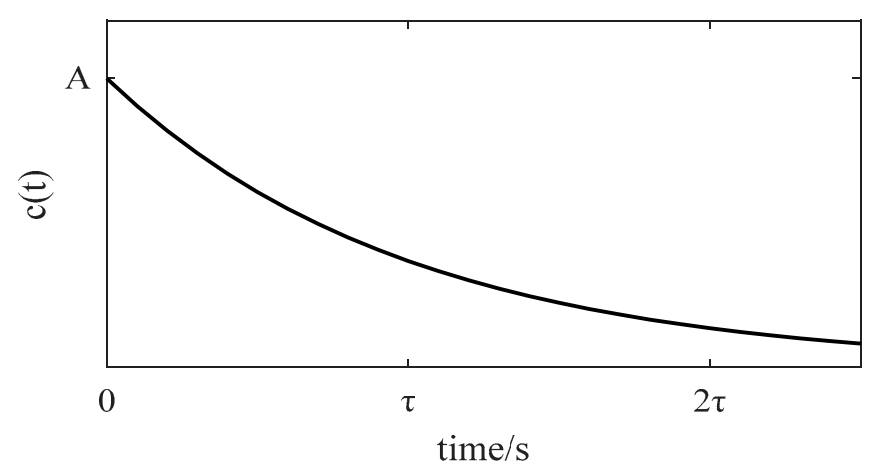

Figure 15. Waveform of the exponential function.

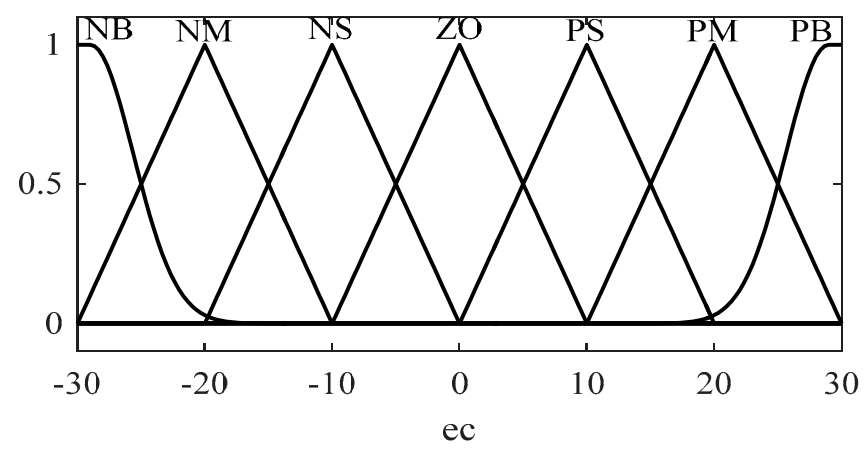

Figure 16. $\Delta f$ of the membership function.

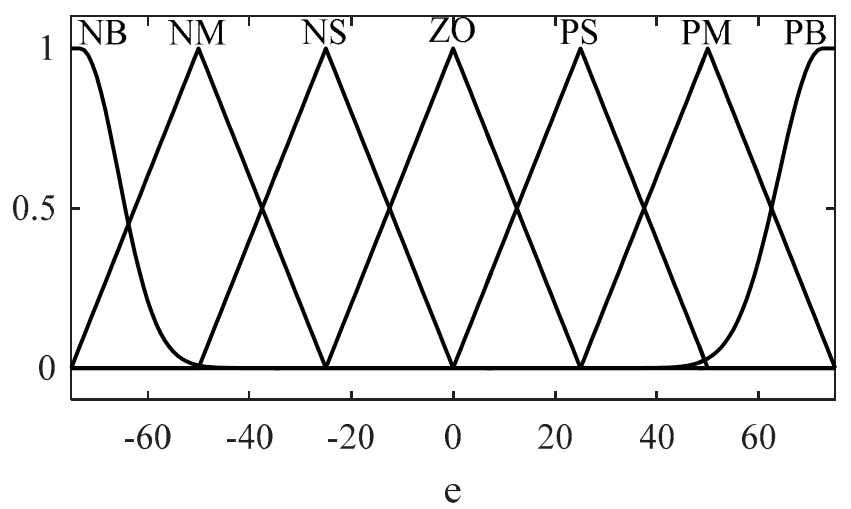

Figure 17. $\mathrm{d} \Delta f / \mathrm{d} t$ of the membership function. 


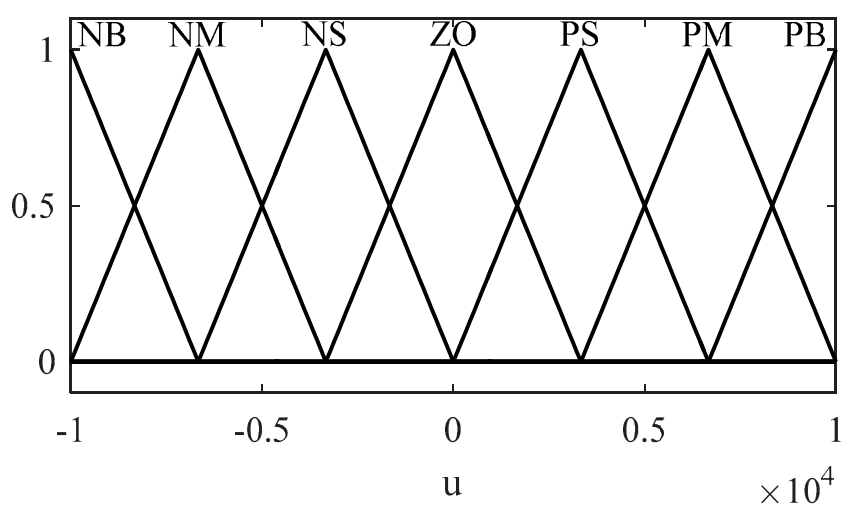

Figure 18. Output $\Delta P_{2}$ of the membership function.

Table 1. Fuzzy logic rules.

\begin{tabular}{|c|c|c|c|c|c|c|c|}
\hline$\Delta f$ & NB & NM & NS & $\mathrm{ZO}$ & PS & $\mathbf{P M}$ & PB \\
\hline NB & PB & PB & PM & PS & $\mathrm{ZO}$ & $\mathrm{ZO}$ & $\mathrm{ZO}$ \\
\hline NM & PB & PB & PM & PS & $\mathrm{ZO}$ & $\mathrm{ZO}$ & $\mathrm{ZO}$ \\
\hline NS & PM & PM & PM & $\mathrm{ZO}$ & $\mathrm{ZO}$ & NS & NS \\
\hline $\mathrm{ZO}$ & PM & PM & PS & $\mathrm{ZO}$ & NS & NM & NM \\
\hline PS & PS & PS & $\mathrm{ZO}$ & NS & NM & NM & NM \\
\hline PM & $\mathrm{ZO}$ & $\mathrm{ZO}$ & $\mathrm{ZO}$ & NS & NM & NB & NB \\
\hline PB & $\mathrm{ZO}$ & $\mathrm{ZO}$ & $\mathrm{ZO}$ & NB & NB & NB & NB \\
\hline
\end{tabular}

\section{Analysis of Simulation and Results}

Based on the overall model of the ship's micro-grid system developed by MATLAB/SIMULINK, we ran a simulation to evaluate the effectiveness of the power distribution and control allocation strategy and the system's operational stability. The input parameters of the simulation were as follows:

(1) The specified outputs of the diesel generator were $100 \mathrm{~kW}, 380 \mathrm{~V}$, and $50 \mathrm{~Hz}$.

(2) The maximum power output of the PV was $15 \mathrm{~kW}$.

(3) The rated capacity of the battery was $200 \mathrm{Ah}, 537 \mathrm{~V}$.

(4) Resistors were used to simulate the system load.

The initial conditions were that the system was operated in parallel on stable status: initial total load $45 \mathrm{~kW}$, PV output $15 \mathrm{~kW}$, diesel generator output $10 \mathrm{~kW}$, and battery output $20 \mathrm{~kW}$. At five seconds, the load was suddenly increased to $80 \mathrm{~kW}$. The frequency response curve of the micro-grid system is shown in Figure 19, and the operational profiles of the different energy modules are shown in Figure 20.

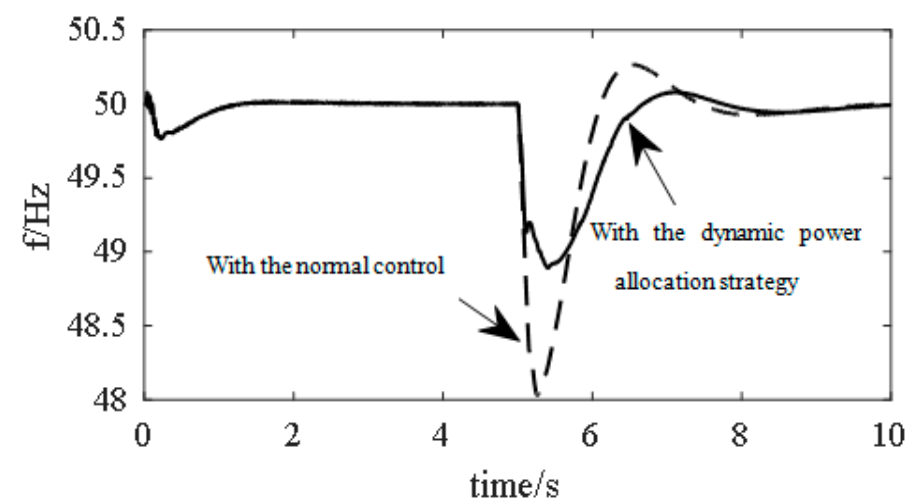

Figure 19. Frequency response curves of the micro-grid system. 
The dotted line in Figure 20 shows that the maximum frequency deviation was $2 \mathrm{~Hz}$ when the load was suddenly increased to $80 \mathrm{~kW}$. The real line indicates the frequency response curve of the micro-grid system with the dynamic power allocation strategy. From the real line, the maximum frequency deviation was $1 \mathrm{~Hz}$ when the load variation suddenly increased to $80 \mathrm{~kW}$. Compared with the two curves, the system frequency fluctuation was decreased by $[(2-1) / 2] \times 100 \%=50 \%$ using the proposed control strategy, proving it could efficiently improve the system's dynamic performance.

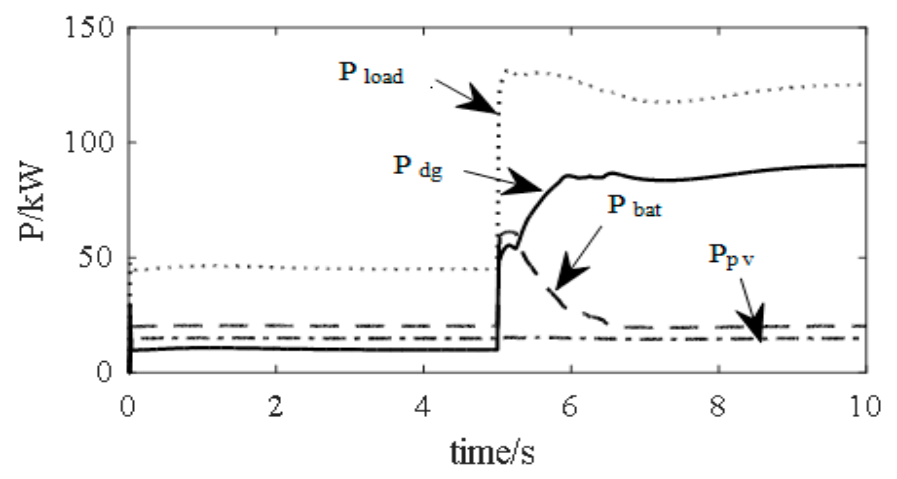

Figure 20. Operational profiles of different energy modules.

As can be seen from the load and power simulations for each power generation unit, presented in Figure 20, at the load mutation moment, the dynamic power reference value of the battery system quickly increased and the power diesel generator was minimized in the working state. At the same time, the dynamic power reference of the battery system decreased and the output power of the diesel generators increased. Finally, the dynamic power reference value of the battery system decreased to zero and all of the increased loads were borne by the diesel generators. Because the output power of the battery system decreased gradually according to the design of the $e$ exponential function, the diesel generators had enough response time for speed regulation, so they did not produce larger frequency fluctuations in the micro-grid system. The whole process of the power distribution system enabled full use of the lithium battery's good instantaneous discharge performance, improved the power quality in the dynamic process of the micro-grid system, and efficiently ensured the system's stability.

The combination of new energy technology and electrical propulsion technology is an effective way to solve the problems of energy saving and greenhouse gas emission reduction of ships. But as a relatively independent unit and regardless of actual structures or grid characteristics, the power grids of ships have the typical characteristics different from the ones of terrestrial regions. Investigation of the coordinated control strategy for different power generation units under different situations is the essential scientific problem that must be developed to ensure the stable economic operation of the ship's micro-grid. This paper investigated a useful strategy to improve the utilization rate of renewable energy under static conditions, reduce the frequency fluctuation of the system under dynamic conditions, and improve the power quality and system stability of the ship's micro-grid.

In the past, Guo et al. had combined the battery with SC as the energy storage system and they investigated the control strategy of the power balance and the optimal energy management in MVDC power system [37]. The system could be used to maintain the MVDC bus voltage within desired margin, which was usually $10 \%$ around the nominal MVDC voltage. The objective of this research was to investigate the battery as the main power supply of cruise ships and investigate the control strategy of the power quality (constant frequency), which could have the optimal energy management in LVAC power system. For the widely used alternating current (AC) electrical propulsion ships, if the above micro-grid system architecture is adopted, a large number of power converters need to be connected to the direct current (DC) grid side to realize the conversion of the electrical energy form. Then the electrical energy utilization rate is low and the cost is high, although the voyage of large ships can be far away, the application prospect is not good. Therefore, the investigated management and 
distribution strategies are used, the ship's AC grid composed of the generator and the new energy is more advantageous, practical, and popularized.

\section{Conclusions}

The combination of new energy technology and electrical propulsion technology is an effective way to solve energy saving and greenhouse gas emission reduction of ships. But as a relatively independent unit, regardless of the actual structures or grid characteristics, ships have typical characteristics different from terrestrial power grids. The coordinated control strategy of different power generation units under different situations is the essential scientific problem that must be solved to ensure the stable economic operation of the ship's micro-grid. This paper investigated a strategy for the ship's micro-grid, which consisted of PV, DG, and a lithium battery. For that, the characteristics of the grid-connected operation of the new energy inverter power system, the ship's power station, and the corresponding dynamic power allocation strategy were proposed. In this study, we successfully constructed a simulation model to integrate the characteristics of a photovoltaic cell, a diesel generator, and a lithium battery (PV/DG/BAT), then investigated using a ship's micro-grid system to combine the three power sources. The constructed model allowed us to explore frequency fluctuations in the multi-energy micro-grid system under dynamic conditions. The dynamic power reference value was easily obtained by fuzzy control and a current compensation algorithm. Via the proposed distribution strategy for dynamic power, under the same conditions the diesel generator had enough response time to regulate its rotating speed, and the output powers had reasonable distribution. When the load was suddenly changed, the proposed strategies reduced the frequency fluctuation by $50 \%$. The proposed strategies could also be used to reduce the frequency fluctuation caused by sudden changes because of the intermittent characteristics of PV power, greatly improving the stability of PV/DG/BAT-based dynamic power.

Author Contributions: Methodology, S.L. and W.Y.; software, S.L., Y.Z., and C.-F.Y.; formal analysis, W.Y., and C.-F.Y.; investigation, W.Y., S.L. and Y.Z.; data curation, Y.Z. and C.-F.Y.; original draft preparation, S.L., and W.Y.; review and editing, W.Y., Y.Z., and C.-F.Y.

Funding: The authors acknowledge the support provided by the National Natural Science Foundation of China (NO. 51679106) and the major science and technology project of Fujian province (NO. 2018H6014). This work was also supported by projects under No. MOST 108-2221-E-390-005 and MOST 108-2622-E-390-002-CC3.

Conflicts of Interest: The authors declare no conflict of interest.

\section{References}

1. O'Rourke, R. Nuclear and Fossil Fuel Powered Surface Ships, Quick Look Analysis: U.S. Naval Nuclear Propulsion Program-CRS Report RL33946; Congressional Research Service: Washington, WA, USA, 2007.

2. O'Rourke, R. Navy Ship Propulsion Technologies: Options for Reducing Oil Use (Background for Congress)-CRS Report RL33360; Congressional Research Service: Washington, WA, USA, 2006.

3. Zhang, H.; Chen, H.J.; Du, X.Z.; Wen, D.S. Photothermal conversion characteristics of gold nanoparticle dispersions. Sol. Energy 2014, 100, 141-147. [CrossRef]

4. Savchuk, O.A.; Carvajal, J.J.; Massons, J.; Aguilo, M.; Diza, F. Determination of photo-thermal conversion efficiency of grapheme and grapheme oxide through an integrating sphere method. Carbon 2016, 103, $134-141$. [CrossRef]

5. Ayad, M.; Aissat, A. Photo-stability of the photons converter applied in the photovoltaic conversion systems. Sol. Energy 2016, 133, 221-225. [CrossRef]

6. Rosa-Clot, M.; Rosa-Clot, P.; Tina, G.M.; Ventura, C. Experimental photovoltaic thermal power plants based on TESPI panel. Sol. Energy 2016, 133, 305-314. [CrossRef]

7. Lee, D.Y.; Cutler, J.W.; Mancewicz, J.; Ridley, A.J. Maximizing photovoltaic power generation of a space-dart configured satellite. Acta Astronaut. 2015, 111, 283-299. [CrossRef]

8. Girish, T.E.; Aranya, S.; Nisha, N.G. Photovoltaic power generation using albedo and thermal radiations in the satellite orbits around planetary bodies. Sol. Energy Mater. Sol. Cells 2007, 91, 1503-1504. [CrossRef] 
9. Wu, Z.; Xia, X.H. Optimal switching renewable energy system for demand side management. Sol. Energy 2015, 114, 278-288. [CrossRef]

10. Kibria, M.A.; Saidur, R.; AI-Sulaiman, F.A.; Aziz, M.M.A. Development of a thermal model for a hybrid photovoltaic module and phase change materials storage integrated in buildings. Sol. Energy 2016, 124, 114-123. [CrossRef]

11. Atmaca, E. Energy management of solar car in circuit race. Turk. J. Electr. Eng.Comput. Sci. 2015, 23, 1142-1158. [CrossRef]

12. Vinnichenko, N.A.; Uvarov, A.V.; Znamenskaya, I.A.; Ay, H.; Wang, T.H. Solar car aerodynamic design for optimal cooling and high efficiency. Sol. Energy 2014, 103, 183-190. [CrossRef]

13. Lan, H.; Wen, S.; Yu, D.C. Optimal sizing of hybrid PV/diesel/battery in ship power system. Appl. Energy 2015, 158, 26-34. [CrossRef]

14. Glykas, A.; Papaioannou, G.; Perissakis, S. Application and cost-benefit analysis of solar hybrid power installation on merchant marine vessels. Ocean Eng. 2010, 37, 592-602. [CrossRef]

15. Tsekouras, G.J.; Kanellos, F.D.; Prousalidis, J. Simplified method for the assessment of ship electric power systems operation cost reduction from energy storage and renewable energy sources integration. IET Electr. Syst. Transp. 2015, 5, 61-69. [CrossRef]

16. Adamo, F.; Andria, G.; Cavone, G.; De Capua, C.; Lanzolla, A.M.L.; Morello, R.; Morello, R.; Spadavecchia, M. Estimation of ship emissions in the port of Taranto. Measurement 2014, 47, 982-988. [CrossRef]

17. Wen, S.; Lan, H.; Yu, D.C.; Fu, Q. Optimal sizing of hybrid energy storage sub-systems in PV/Diesel ship power system using frequency analysis. Energy 2017, 140, 198-208. [CrossRef]

18. Ruoli, T. Large-scale photovoltaic system on green ship and its MPPT controlling. Sol. Energy 2017, 157, 614-628.

19. Lee, K.J.; Shin, D.; Yoo, D.W.; Choi, H.K.; Kim, H.J. Hybrid photovoltaic/diesel green ship operating in standalone and grid-connected mode-experimental investigation. Energy 2013, 49, 475-483. [CrossRef]

20. Sun, Y.; Qiu, Y.; Yuan, C.; Tang, X.; Wang, Y.; Jiang, Q. Research on the transient characteristic of photovoltaics-ship power system based on PSCAD/EMTDC. In Proceedings of the International Conference on Renewable Energy Research and Applications (ICRERA), Palermo, Italy, 22-25 November 2015; pp. 397-402.

21. Yu, W.N.; Li, D.; Zheng, W.M. Research and development of energy control system for solar tour vessels. China Shipbuild. 2013, 54, 177-183.

22. Yu, W.N.; Liao, W.Q.; Yang, R.F.; Li, S.W. Research and development of multi-energy ship micro-grid energy control system based on solar lithium battery and diesel generator set. China Shipbuild. 2017, 58, 170-176.

23. Banaei, M.R.; Alizadeh, R. Simulation-Based Modeling and Power Management of All-Electric Ships Based on Renewable Energy Generation Using Model Predictive Control Strategy. IEEE Intell. Transp. Syst. Mag. 2016, 8, 90-103. [CrossRef]

24. Gao, D.Z.; Shen, A.D.; Yan, J.X.; Huang, X.X. Energy Management and Control Strategy for Hybrid Electric Ships. J. Shanghai Marit. Univ. 2015, 36, 70-74.

25. Kong, L.Z.; Tang, X.S.; Qi, Z.P.; Lin, N. Research on energy storage dynamic energy scheduling strategy of Photovoltaic-Diesel Generator-Battery micro-grid system. Power Syst. Prot. Control 2012, 40, 6-12.

26. Ding, D.; Liu, Z.Q.; Yang, S.L.; Wu, X.G.; Li, T.T. Auxiliary AGC Frequency Modulation Method for Battery Energy Storage System Based on Fuzzy Control. Power Syst. Protec. Control 2015, 43, 81-87.

27. Li, W.K. Mathematical Modeling of Diesel Generator Sets and Its Power Compensation Technology; Harbin Institute of Technology: Harbin, China, 2013.

28. Zhai, D.; An, L.W.; Dong, L.X.; Zhang, Q.L. Robust Adaptive Fuzzy Control of a Class of Uncertain Nonlinear Systems with Unstable Dynamics and Mismatched Disturbances; IEEE Transactions on Cybernetics: Piscataway, NJ, USA, 2017.

29. Liao, W.Q.; Zhang, R.C.; Yu, W.N.; Wang, G.L. Prediction of output power of photovoltaic based on similar samples and principal component analysis. J. Sol. Energy 2016, 37, 2377-2385.

30. Benhamed, S.; Ibrahim, H.; Belmokhtar, K.; Hosni, H. Dynamic Modelling of Diesel Generator Based on Electrical and Mechanical Aspects. In Proceedings of the IEEE Electrical Power and Energy Conference (EPEC), Ottawa, ON, Canada, 12-14 October 2016.

31. Joga Rao, G.; Shrivastava, S.K.; Mangal, D.K. Coordinated V-f and P-Q Control of Solar Photovoltaic Generators with MPPT and Battery Storage in Microgrids. IEEE Trans. Smart Grid 2014, 5, 1270-1281. 
32. Abada, S.; Marlair, G.; Lecocq, A.; Petit, M.; Sauvant-Moynot, V.; Huet, F. Safety focused modelling of lithium-ion batteries: A. review. J. Power Sources 2016, 306, 178-192. [CrossRef]

33. Khan, M.M.S.; Faruque, M.O.; Newaz, A. Fuzzy Logic Based Energy Storage Management System for MVDC Power System of All Electric Ship; IEEE Transactions on Energy Conversion: Piscataway, NJ, USA, 2017.

34. Sun, L.; Yue, Y.T. Research of fuzzy PD control algorithm based on DSP. China Electro-Tech. Soc. 2015, 30, 465-468.

35. Song, Q.; Wu, Y. Study on the Robustness Based on PID Fuzzy Controller. In Proceedings of the 2017 International Conference on Computing Intelligence and Information System (CIIS), Nanjing, China, 21-23 April 2017; pp. 142-145.

36. Qiang, G.; Junfeng, H.; Wei, P. PMSM Servo Control System Design Based on Fuzzy PID”. In Proceedings of the 2017 2nd International Conference on Cybernetics, Robotics and Control (CRC), Chengdu, China, 21-23 July 2017; pp. 85-88.

37. Guo, Y.; Khan, M.M.S.; Faruque, M.O.; Sun, K. Fuzzy logic based energy storage supervision and control strategy for mvdc power system of all electric ship. In Proceedings of the 2016 IEEE Power and Energy Society General Meeting (PESGM), Boston, MA, USA, 17-21 July 2016.

(C) 2019 by the authors. Licensee MDPI, Basel, Switzerland. This article is an open access article distributed under the terms and conditions of the Creative Commons Attribution (CC BY) license (http://creativecommons.org/licenses/by/4.0/). 